\title{
Clinical Presentation and Frequency of Risk Factors in Patients with Breast Carcinoma in Pakistan
}

\author{
Zahid Ali Memon ${ }^{1}$, Qurrat-ul-Ain ${ }^{2 *}$, Ruba Khan ${ }^{2}$, Natasha Raza' ${ }^{2}$ Tooba Noor ${ }^{2}$
}

\begin{abstract}
Background: Breast cancer is known to be one of the most prevalent cancers among women in both developing and developed countries.The incidence of breast cancer in Pakistan has increased dramatically within the last few years and is the second country after Israel in Asia to have highest proportional cases of breast cancer. However, there are limited data for breast cancer available in the literature from Pakistan. Objectives: The study was conducted to bring to light the common clinical presentation of breast cancer and to evaluate the frequency of established risk factors in breast carcinoma patients and furthermore to compare the findings between premenopausal and postmenopausal women in Pakistan. Materials and Methods: A 6 months (from July 2012 to Dec 2012) cross sectional survey was conducted in Surgical and Oncology Units of Civil Hospital, Karachi. Data were collected though a well developed questionnaire from 105 female patients diagnosed with carcinoma of breast and analyzed using SPSS version 17. Institutional ethical approval was obtained prior to data collection. Results: Out of 105 patients, 43 were premenopausal and 62 were postmenopausal, 99 being married. Mean age at diagnosis was $47.8 \pm 12.4$ years. A painless lump was the most frequent symptom, notived by $77.1 \%(n=81)$. Some $55.2 \%(n=58)$ patients had a lump in the right breast and $44.8 \%(n=47)$ in the left breast. In the majority of cases, the lump was present in upper outer quadrant $41.9 \%(n=44)$. Mean period of delay from appearance of symptoms to consulting a doctor was $5.13 \pm 4.8$ months, from the shortest 1 month to the longest 36 months. Long delay (>3 months) was the most frequent figure 41.9\%. Considering overall risk factors most frequent were first pregnancy after 20 years of age (41\%), physical breast trauma $(28.6 \%)$, lack of breast feeding $(21.9 \%)$, and early menarche $<11$ years $(\mathbf{1 9 \%})$, followed by null parity $(\mathbf{1 6 . 2 \% )}$, consumption of high fat diet $(\mathbf{1 5 . 2 \%})$, family history of breast cancer or any other cancer in first degree relatives $(\mathbf{9 . 5 \%}$ and $13.3 \%$, respectively). Some of the less common factors were late menopause $>54$ years $(8.6 \%)$, use of oral contraceptive pills $(\mathbf{1 0 . 5 \%})$, use of hormone replacement therapy $(4.7 \%)$,smoking $(4.7 \%)$ and radiation $(0.96 \%)$. Significant differences $(\mathbf{p}<\mathbf{0 . 0 0 5})$ were observed between pre and post menopausal women regarding history of physical breast trauma, practice of breast feeding and parity. Conclusions: A painless lump was the most frequent clinical presentation noted. Overall age at first child $>20$ years, physical breast trauma, lack of breast feeding,early menarche $<11$ were the most frequent risk factors. Physical breast trauma, lower parity, a trend for less breast feeding had more significant associations with pre-menopausal than post-menopausal onset. Increase opportunity of disease prevention can be obtained through better understanding of clinical presentation and risk factors important in the etiology of breast cancer.
\end{abstract}

Keywords: Breast cancer - lump in breast - causes of breast cancer - common age of breast cancer

Asian Pac J Cancer Prev, 16 (17), 7467-7472

\section{Introduction}

Cancer is included in that class of diseases in which the cell growth does not stay in control. There are more than 100 different categories of cancers depend on type of cells principally affected. In the body normally cells follow an orderly route of growth ,division and death. Unlike normal ,Cancer is ultimately the result of the uncontrollable growth of these cells which just grow and do not die. Apoptosis is the programmed cell death, and when this process disturbed, cancer initiates. Cancer cells do not follow this pattern of normal cells and instead continue to grow and divide. This leads to out of control mass growth of abnormal cells (What Is Cancer? What Causes Cancer?).

A malignant tumor that has developed from these abnormal cells in the breast is called "breast cancer". Usually breast cancer begins either in the cells present in the lobules, which are glands that produce milk, or the ducts, which are the channels that drain milk from the lobules to the nipple. Breast cancer can also begin in the stromal tissues, which is less common and include 
the breast's fatty and fibrous connective tissues ("Breast Cancer Treatment, Shaukat, Ismail, abd Mehmood, 2013).

More than one million new cases of breast cancer in women are diagnosed every year. It is the most common cancer of women in both developing and developed countries (Bray, McCarron, abd Parkin, 2004; Yip, Taib, abd Mohamed, 2006).According to the World Health Organization the occurrence of breast cancer would go up by 2020 (Boyle,Levin, abd Cancer, 2008).Geographically incidence and mortality rate may vary and developed countries report more but in low- middle income countries dramatic changes in incidence and mortality has been observed (Kim et al., 2007).Pakistan is one of those countries which has the highest rate of breast cancer in Asia and one out of every nine women in Pakistan is at risk of having this disease (Sohail abd Alam, 2007).More than 90,000 of the 1 million global cases of breast cancer are from Pakistan (Laaleen, 2009) and it is the most occurring cancer of women in Karachi accounting for one third of female cancers (Bhurgri et al., 2000) .

A lump in the breast, change in breast shape dimpling or lumpiness of the skin, red scaly patch of skin or fluid

\section{Table 1. Descriptive Statistics}

\begin{tabular}{llrc}
\hline Variable & & $\mathrm{N}$ & $\%$ \\
\hline Education & Illiterate & 53 & 50.4 \\
& Primary & 40 & 38 \\
& Secondary & 12 & 11.4 \\
Marital Status & Married & 99 & 94.3 \\
& Unmarried & 6 & 5.7 \\
Menstrual Status & Pre-menopausal & 43 & 41 \\
& Post-menopausal & 62 & 59 \\
\hline
\end{tabular}

Table 2. Distribution of Involved Breast, Clinical Presentation and Site of Lump in Patients

\begin{tabular}{lrrr}
\hline Characteristics & $\begin{array}{c}\text { Premenopausal } \\
(\mathrm{n}=43)\end{array}$ & $\begin{array}{c}\text { Postmenopausal } \\
(\mathrm{n}=62)\end{array}$ & $\begin{array}{c}\text { Total } \\
105\end{array}$ \\
\hline Breast involved & & & \\
Right & $26(24.8 \%)$ & $32(30.4 \%)$ & $58(55.2 \%)$ \\
Left & $17(16.2 \%)$ & $30(28.6 \%)$ & $47(44.8 \%)$ \\
Symptoms & & & \\
Painless lump & $35(33.3 \%)$ & $46(43.8 \%)$ & $81(77.1 \%)$ \\
Others symptoms & $8(7.61 \%)$ & $16(15.2 \%)$ & $24(22.9 \%)$ \\
Site of lump & & & \\
Upper Outer & $19(18.1 \%)$ & $25(23.8 \%)$ & $44(41.9 \%)$ \\
Upper Inner & $6(5.71 \%)$ & $10(9.52 \%)$ & $16(15.2 \%)$ \\
Lower outer & $5(4.76 \%)$ & $6(5.71 \%)$ & $11(10.5 \%)$ \\
Lower inner & $3(2.85 \%)$ & $5(4.76 \%)$ & $8(7.76 \%)$ \\
Central & $10(9.52 \%)$ & $16(15.2 \%)$ & $26(24.7 \%)$ \\
\hline
\end{tabular}

coming from the nipple are the signs of breast cancer ("Breast Cancer Treatment "). There may be pain in bones, shortness of breath, yellow skin, or the lymph nodes might get swollen if the disease is spread (Christobel, 2009).

There are various risk factors which are responsible for the differences in prevalence rates, these include nonmodifiable and modifiable risk factors.Gender, genetic susceptibility, history of breast cancer, age, ethnicity, and menstrual history are the non-modifiable risk factors (Educationis, 2011).Identified modifiable risk factors include: socio-demographic profiles, lifestyle patterns, factors involved in reproduction, anthropometric status, and their diet pattern (Kluttig abd Schmidt-Pokrzywniak, 2009).

lack of awareness concerning clinical presentation and significant lack of knowledge about the associated risk factors play an enormous role in too-late to effective diagnosis of breast cancer. So, the primary step towards early detection of the breast cancer is acquainting and educating the women about the clinical presentation and risk factors of breast cancer. This will help the women to be able to judge their risks and take relevant measures (Ahmed, Mahmud, Hatcher, abd Khan, 2006).

Current study was carried out to find out the most frequent clinical presentation and common risk factors which are prevailing in females of our society furthermore to compare the findings between pre and post menopausal women diagnosed as breast carcinoma so that women having those risks can evaluate themselves and get their screening done to ensure an early diagnosis and this will eventually reduce the occurrence of disease.

\section{Materials and Methods}

A cross Sectional survey was conducted from July 2012 to Dec 2012, in Surgical and Oncology Units of Civil Hospital Karachi, Pakistan. Total 105 female patients diagnosed as carcinoma of breast of any type were included through convenient sampling. The data was collected with the help of questionnaires developed from the literature review and expert opinion. Patients who have been diagnosed with breast cancer were included in the study while patients, who have been diagnosed with benign tumors or any other abnormality of the breast, were not included in the survey. Data on clinical presentation and complete history was taken by the researcher itself and the patients were evaluated for all known risk factors. To keep research completely ethical, a verbal consent was taken from each patient before filling the forms. Institutional ethical approval was also taken prior to the study. The collected data was analyzed using SPSS v.17.

Table 3a. Relation of Risk-factors with Premenopausal and Postmenopausal Women

\begin{tabular}{|c|c|c|c|c|c|c|c|}
\hline \multicolumn{2}{|c|}{ Risk Factors } & \multicolumn{2}{|c|}{ Premenopausal } & \multicolumn{2}{|c|}{ Postmenopausal } & \multirow[t]{2}{*}{$\mathrm{X}^{2}$ value } & \multirow[t]{2}{*}{$\mathrm{p}$-value } \\
\hline & & $\mathrm{N}$ & $\%$ & $\mathrm{~N}$ & $\%$ & & \\
\hline \multirow[t]{2}{*}{ Breastfeeding } & Yes & 24 & $61.50 \%$ & 53 & $-86.90 \%$ & 8.63 & 0.003 \\
\hline & No & 15 & $-38.50 \%$ & 8 & $13.10 \%$ & & \\
\hline \multirow[t]{2}{*}{ Trauma } & Yes & 17 & $-39.50 \%$ & 13 & $-21.70 \%$ & 3.784 & 0.049 \\
\hline & No & 26 & $-60.50 \%$ & 47 & $-78.30 \%$ & & \\
\hline
\end{tabular}


Table 3b. Relation of Reproductive Risk-factors with Premenopausal and Postmenopausal Women

\begin{tabular}{lccrc}
\hline Risk Factors & $\begin{array}{c}\text { Premenopausal } \\
(\mathrm{n}=43)\end{array}$ & $\begin{array}{c}\text { Postmenopausal } \\
(\mathrm{n}=62)\end{array}$ & t-test value & p-value \\
\hline Parity & $3.0 \pm 0.89$ & $5.0 \pm 0.96$ & 10.078 & $<0.01$ \\
Age of menarche & $12.83 \pm 1.27$ years & $12.9 \pm 1.61$ years & 0.615 & 0.54 \\
Age at first child & $22.51 \pm 4.8$ years & $21.58 \pm 7.6$ years & 0.399 & 0.691 \\
\hline
\end{tabular}

\section{Results}

Mean age of the patients at diagnoses in our study was found to be $47.8 \pm 12.4$ years with a minimum age of 17 years and maximum of 71 years. Mostly were diagnosed between the age of 40 and 60 years. Age distribution of the patients is given in [Figure 1].

Half of the patients $50.4 \%(n=53)$ were illiterate i.e. they have never gone to school ever in their lives. Majority were married $(94.3 \%, \mathrm{n}=99)$ and housewives. Out of 105 patients 43 were premenopausal and 62 were postmenopausal. Descriptive statistics of patients are shown in[Table 1]. Mean age at diagnosis of patients at premenopausal is $37.4 \pm 7.63$ years and $55 \pm 9.5$ years at postmenopausal.A painless lump in breast was noticed in $77.1 \%(n=81)$ of presented patients while in $22.9 \%(n=24)$ other breast symptoms (like nipple discharge, any change in shape and color of breast or nipple) along with a breast lump in a breast were observed. About 55.2\% $(\mathrm{n}=58)$ patients had a lump in the right breast and $44.8 \%(n=47)$ patients had a lump in the left breast. In the majority of the patients, the lump was present in upper outer quadrant $41.9 \%(n=44)$ [ Table 2].

Mean duration of delay from symptoms noticed to consult the doctor was $5.13 \pm 4.8$ months. from shortest 1 month to longest 36 months. Duration of delay was observed to be no delay ( $<1$ month) in $27.6 \%$ ( $\mathrm{n}=29)$, short delay (1-3 months) in $30.4 \%(\mathrm{n}=32)$ and long delay (>3 months) in $41.9 \%(n=44)$ of patients .

According to the study, Overall age at first pregnancy after 20 years was the most frequent risk factor (41\%) followed by physical breast trauma (28.6\%), Lack of breast feeding $(21.9 \%)$, and early menarche<11 years $(19 \%)$. Overall frequencies of different positive risk factors are presented in [Figure 2] .

Mean age of patients at menarche and menopause was as old as $12.96 \pm 1.60$ years and $46.35 \pm 6.65$ years respectively and Mean age at childbirth was $21.92 \pm 6.67$ while no significant difference was found between premenopausal and postmenopausal females regarding age at menarche and age at first child.[Table 3a] There is no significant difference in risk factors between premenopausal and postmenopausal women except for physical trauma to breast was more in premenopausal women $(39.6 \%)$,practice of breast feeding in postmenopausal women $(86.9 \%)$ and parity ,with high mean parity in postmenopausal than in premenopausal women. [Table 3b]. For comparison between pre and post menopausal women other factors (HRT, smoking, and radiation) had so minimal frequency that statistical association could not be calculated .Statistical test was

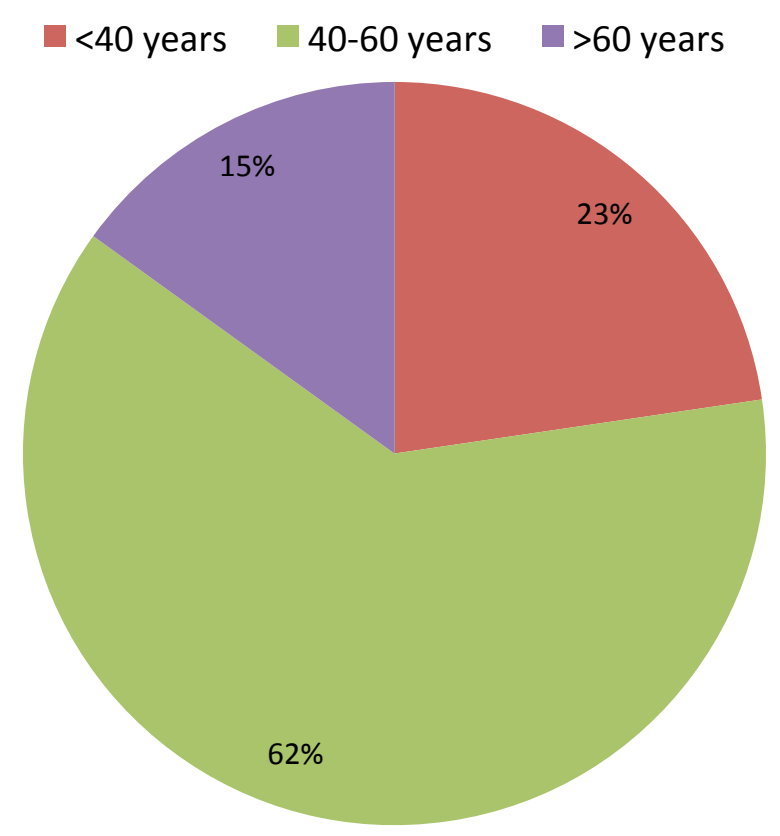

Figure 1. Age Distribution of the Patients

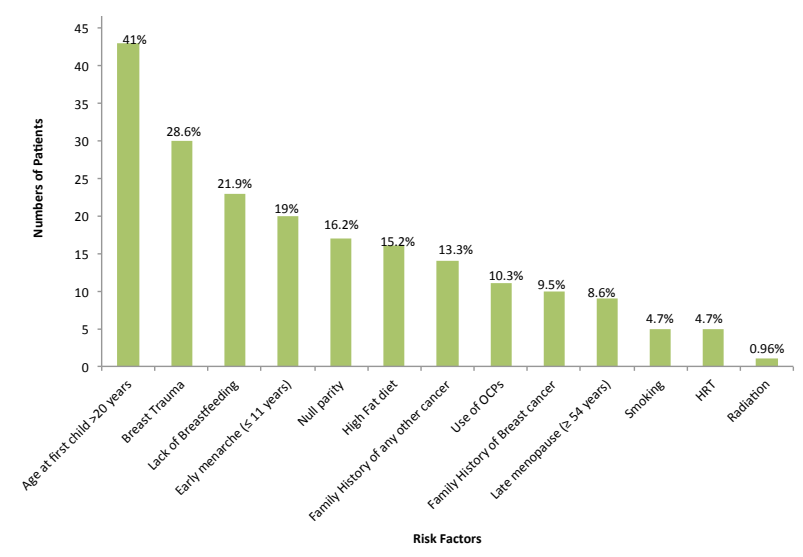

Figure 2. Overall Positive Risk Factors

applicable in High fat diet and overall Family history of breast cancer or any cancer, however tests were insignificant ( $\mathrm{p}$-value $>0.05$ ).

\section{Discussion}

For developing breast cancer female gender is the key risk factor. Female hormone estrogen and progesterone are somewhat responsible for increased exposure of women to breast cancer due to their growth promoting effects (Fregene and Newman, 2005) Older women exhibit more risk of developing breast cancer but in our study most of the women were among 40-60 years age group with 
mean age of presentation was $47.8 \pm 12.4$ years which is comparable with the finding of a local study (Mamoon, Sharif, Mushtaq, Khadim, and Jamal, 2009)and mostly were post menopausal at the time of diagnose (59\%) consistent with the outcome of a non local study (Guvenc, Guvenc, Tastan, and Akyuz, 2012). Younger age at disease presentation in Pakistan in contrast with western world requires prompt actions in the field of screening and early diagnosis to reduce disease incidence and increase opportunityof timely treatment.

Lump in the breast was the chief presenting complaint of all the women in this study as reported in various studies (Bhoo Pathy et al., 2011; Lee et al., 2012; McCormack and dos Santos Silva, 2006).Upper outer quadrant was the major site involved of either side $(\mathrm{n}=44)$.Among patients $55.2 \%(n=58)$ had right sided lump and $44.8 \%(n=47)$ had left sided which is nearly similar with the results of study conducted in Warangal (Surakasula, Nagarjunapu, and Raghavaiah, 2014) while in a regional study left side breast affected more ( $52.2 \%$ ) than right side $(44.8 \%)$ and $2.90 \%$ females had bilateral breast cancer (Baloch et al., 2012). This signifies the importance of self breast examination among general population so that people having lump in breast seek immediate medical advice.

Evaluating frequency of established risk factors , the results of our survey revealed that $41 \%$ of patients experienced their first pregnancy after 20 years and most belongs to postmenopausal group while in a study conducted at three hospitals of Pakistan most of the patients had given their first live birth before 20 years of age and majority were postmenopausal (Saria, Mirza, Habib, abd Zubair, 2010)Results of this study showed physical trauma to breast was the second most common risk factor overall (28.6\%)while positive history of physical breast trauma was significantly higher in premenopausal patients $(31.5 \%)$ than in postmenopausal patients $(21.7 \%)$ consistent with results of study took place at the North Lancashire Breast Screening Service which reported that physical trauma history was more positive in cases as compared to controls (Rigby, Morris, Lavelle, Stewart, abd Gatrell, 2002).Practicing breast feeding was believed to minimize the risk of breast cancer in both preand post-menopausal patients. The risk of breast cancer is relatively reduced by $4 \%$ if a woman breast feeds her babies for longer duration, ( i.e. every 12 months of breastfeeding) (Butt et al., 2012). and in our study lack of breast feeding was the third most frequent factor among patients $(21.9 \%)$ and significantly less trend of breast feeding was found in premenopausal females ( 61.5\%) than in postmenopausal group (86.9\%).

Studies reported that early menarche and late menopause increases the risk of developing breast cancer (McPherson, Steel, abd Dixon, 2000).In current study overall early menarche ( $\leq 11$ years) and late menopause ( $>54$ years) was seen in $19 \%$ and $8.6 \%$ women respectively but early menarche was found more frequent in postmenopausal women $20.9 \%$ than in premenopausal $16.2 \%$ showingsimilarity with the results of a local study (Saria et al., 2010).Nulliparity increases the lifetime incidence of breast cancer (Ferlay, Hery, Autier, abd Sankaranarayanan, 2010).In present study nulliparity was observed in $16.5 \%$ of all patients comparable with the resultsof another study carried out in Saudia Arab (Amin, Al Mulhim, abd Al Meqihwi, 2009).

In breast cancer pathophysiology, there is an increasing evidence for a role for dietary factors, There is a association between diet and breast cancer, including an increased risk with a high fat diet (Blackburn abd Wang, 2007). In our study consumption of high fat diet was reported in $15.2 \%$ women highlighting that due attention should be given on dietary habits of general population too and requirement of future large studies regarding this aspect.

Oral contraceptive pills were taken by $10.5 \%$ patients and hormone replacement therapy by only $4.7 \%$ patients .Nearly reverse percentages were noticed in other survey showing that only $3.8 \%$ females used birth control pills while hormone replacement therapy were taken by $10.5 \%$ of patients (Guvenc et al., 2012).

In recent study family history of breast cancer and family history of any cancer other than breast cancer in first degree relative was presented in $9.5 \%$ and 13.3 $\%$ respectively while study done by Romeo et all demonstrated that family background in first degree was $6.6 \%$ which is nearly similar to this study and for another cancer was $32.4 \%$ (Romero, Santillan, Olvera, Morales, abd Ramirez, 2008).Most western literature and local literature have shown increased risk for breast cancer if one had affected 1 stdegree relative (Cancer, 2001). While a local study published in 2010 did not find increase risk of breast cancer in cases that had positive history of breast cancer in 1st degree relatives. (Butt et al., 2010).

Smoking contributed only in $4.7 \%$ of patients which is consistent with the findings of another study in which smoking was minor factor (McPherson et al., 2000) while smoking was among the most frequent risk factor of breast cancer (28.9\% ) according to a study published in 2008 (Romero et al., 2008). In general population exposure to ionizing radiation is a recognized risk factor, with experience of radiation in adulthood conferring a smaller risk than in childhood and adolescence (Ronckers, Erdmann, abd Land, 2005)but in the present study radiation exposure was found only in $0.96 \%$ of patients. Literature showed that as compared to no exposure increasing number of radiographs before age 30 years reported more risk of breast cancer (Pijpe et al., 2012).

Previous studies explained that increase parity decreases the risk of breast cancer and as compared to women having no children women having 5 or more children have half the risk. .in our study mean number of children was $3.87 \pm 2.89$ while significant higher mean value was found in postmenopausal women $(n=5.0 \pm 0.96)$ than in premenopausal women $(n=3.0 \pm 0.89)$ (Lambe et al., 1996).

A painless lump in the breast was the most frequent clinical presentation noticed. Overall age at first child $>20$, physical breast trauma, lack of breast feeding ,early menarche $<11$ were the most frequent risk factors. Physical breast trauma ,less parity, less trend of breast feeding, had significant association with pre-menopausal onset of breast cancer than the post-menopausal onset.

Increase opportunity of disease prevention can 
be obtained through better understanding of clinical presentation and risk factors important in the etiology of breast cancer. Awareness programs should be conducted in regional languages regarding risk factors and screening methods for better understanding. Self breast examination should be encouraged among females of all ages. The study will be useful addition to current understanding of epidemiology of breast cancer in Pakistan .Studies done on wider scale are needed to establish the findings of the study.

\section{Acknowledgements}

We are Very thankful to Dr.MUHAMMAD SIKANDER GHAYAS KHAN (Assistant Professor ,Riphah College of Rehabilitation Sciences ,Riphah International University Lahore.) and MrsMadihaSikander,for their valued support, unstinted assistance, timely guidance, befitting facilities and great deal of moral support.

\section{References}

Ahmed F, Mahmud S, Hatcher J, abd Khan SM (2006). Breast cancer risk factor knowledge among nurses in teaching hospitals of Karachi, Pakistan: a cross-sectional study. BMC Nursing, 5, 6.

Amin TT, Al Mulhim A, abd Al Meqihwi A (2009). Breast cancer knowledge, risk factors and screening among adult Saudi women in a primary health care setting. Asian Pac J Cancer Prev, 10, 133-8.

Baloch AH, Shuja J, Daud S, et al (2012). Various aspects, patterns and risk factors in breast cancer patients of Balochistan. Asian Pac J Cancer Prev, 13, 4013-6.

Bhoo Pathy N, Yip CH, Taib NA, et al (2011). Breast cancer in a multi-ethnic Asian setting: Results from the SingaporeMalaysia hospital-based breast cancer registry. Breast, 20, 75-80.

Bhurgri Y, Bhurgri A, Hassan SH, et al (2000). Cancer incidence in Karachi, Pakistan: first results from Karachi cancer registry. Int $J$ Cancer, $\mathbf{8 5}$, 325-9.

Blackburn GL, abd Wang KA (2007). Dietary fat reduction and breast cancer outcome: results from the Women's Intervention Nutrition Study (WINS). Am J Clin Nutrit, 86, 78-881.

Boyle P, Levin B, abd Cancer IAfRo. (2008). Dunya kanser raporu 2008: Uluslararası Kanser Arastırma Kurumu.

Bray F, McCarron P, abd Parkin DM (2004). The changing global patterns of female breast cancer incidence and mortality. Childhood, 4.

Breast Cancer Treatment (November 25, 2014). Turning Discovery Into Health ${ }^{\circledR}$ Retrieved 3rd january, 2015, from http://www.cancer.gov/cancertopics/pdq/treatment/breast/ Patient/page1/AllPages

Butt Z, Haider SF, Arif S, et al (2012). Breast cancer risk factors: A comparison between pre-menopausal and postmenopausal women. Breast cancer.

Butt Z, Shahbaz U, Naseem T, et al (2010). Reproductive risk factors for female breast cancer: a case-control study. Annals of King Edward Medical University, 15.

Collaborative Group on Hormonal Factors in Breast Cancer. (2001). Familial breast cancer: collaborative reanalysis of individual data from 52 epidemiological studies including 58 209 women with breast cancer and 101986 women without the disease. Lancet, 358, 1389-99.

Christobel MS, Sunil jassal (2009). Brest cancer. New York,
UK.: Oxford University Press.

Educationis B. (2011). Prevalence of the known risk factors in women diagnosed with breast cancer at queen ii hospital, maseru.

Ferlay J, Hery C, Autier, P, abd Sankaranarayanan R (2010). Global burden of breast cancer breast cancer epidemiology.

Fregene A, abd Newman LA (2005). Breast cancer in sub-saharan africa: how does it relate to breast cancer in african-american women? Cancer, 103, 1540-50.

Guvenc I, Guvenc G, Tastan S, abd Akyuz A (2012). Identifying women's knowledge about risk factors of breast cancer and reasons for having mammography. Asian Pac J Cancer Prevention, 13, 4191-7.

Kim Y, Choi JY, Lee KM, et al (2007). Dose-dependent protective effect of breast-feeding against breast cancer among ever-lactated women in Korea. Eur J Cancer Prev, 16, 124-9.

Kluttig A, abd Schmidt-Pokrzywniak A (2009). Established and suspected risk factors in breast cancer aetiology. Breast Care, 4, 82-87.

Laaleen. (2009). why do we have highest rates of Breast cancer in asia Thanks that Laaleen wrote Retrieved March 23, 2014, from http://laaleen.blogspot.com/2009/04/why-do-we-havehighest-rates-of-breast.html

Lambe M, Hsieh CC, Chan HW, et al (1996). Parity, age at first and last birth, and risk of breast cancer: a population-based study in Sweden. Breast Cancer Res Treatment, 38, 305-11.

Lee DS, Yoon SY, Looi LM, et al (2012). Comparable frequency of BRCA1, BRCA2 and TP53 germline mutations in a multi-ethnic Asian cohort suggests TP53 screening should be offered together with BRCA1/2 screening to early-onset breast cancer patients. Breast Cancer Res, 14, 66.

Mamoon N, Sharif MA, Mushtaq S, Khadim MT, abd Jamal $\mathrm{S}$ (2009). Breast carcinoma over three decades in northern Pakistan-are we getting anywhere? Breast, 59, 835-8.

McCormack VA, abd dos Santos Silva I (2006). Breast density and parenchymal patterns as markers of breast cancer risk: a meta-analysis. Cancer Epidemiol Biomarkers abd Prev, 15, 1159-69.

McPherson K, Steel C, abd Dixon J (2000). ABC of breast diseases: breast cancer-epidemiology, risk factors, and genetics. BMJ: British Medical Journal, 321, 624.

Pijpe A, Andrieu N, Easton DF, et al (2012). Exposure to diagnostic radiation and risk of breast cancer among carriers of BRCA1/2 mutations: retrospective cohort study (GENERAD-RISK). Bmj, 345.

Rigby J, Morris J, Lavelle J, Stewart M, abd Gatrell A (2002). Can physical trauma cause breast cancer? Eur J Cancer Prev, 11, 307-11.

Romero FMS, Santillan AL, Olvera HP, Morales SM, abd Ramirez MV (2008). Frequency of risk factors in breast cancer. Ginecol Obstetricia De Mexico, 76, 667.

Ronckers CM, Erdmann CA, abd Land CE (2005). Radiation and breast cancer: a review of current evidence. Breast Cancer Res, 7, 21-32.

Saria MS, Mirza MR, Habib L, abd Zubair M (2010). Breast cancer among pakistani women in referral Hospitals: an overview of risk factors. Ibrahim Med Coll J, 4, 1-3.

Shaukat U, Ismail M, abd Mehmood N (2013). Epidemiology, major risk factors and genetic predisposition for breast cancer in the Pakistani population. Asian Pac J Cancer Prev, 14, 5625-9.

Sohail S, abd Alam SN (2007). Breast cancer in pakistanawareness and early detection. J Coll Physicians Surgeons Pakistan, 17, 711.

Surakasula A, Nagarjunapu GC, abd Raghavaiah K (2014). A comparative study of pre-and post-menopausal breast cancer: 
Zahid Ali Memon et al

Risk factors, presentation, characteristics and management. J Res Pharmacy Practice, 3, 12.

What Is Cancer? What Causes Cancer? MNT Knowledge Center, Retrieved $3^{\text {rd }}$ Junvery 2015, 2015, from http://www. medicalnewstoday.com/info/cancer-oncology/

Yip, C. H., Taib, N., abd Mohamed, I. (2006). Epidemiology of breast cancer in Malaysia. Asian Pac J Cancer Prev, 7, 369. 